\title{
The role of removable appliances in contemporary orthodontics
}

\author{
S. J. Littlewood, ' A. G. Tait, ${ }^{2}$ N. A. Mandall, ${ }^{3}$ and D. H. Lewis, ${ }^{4}$
}

\begin{abstract}
The contemporary uses of removable appliances are considerably more limited than in the past. This article discusses possible reasons for their declining use, including recognition of their limitations. It is possible to achieve adequate occlusal improvement with these appliances providing that suitable cases are chosen. Specific indications for their appropriate use on their own in the mixed dentition are presented. Removables can also be used as an adjunct to more complex treatments, to enhance the effect of fixed appliances, headgear or in preparation for functional appliances. Further research is required to confirm whether their use in conjunction with more complex treatments enhances the quality and efficiency of treatment or not.
\end{abstract}

\begin{abstract}
Objective
The aim of this paper is to describe the role of removable appliances in modern, contemporary orthodontics, and to discuss how this role has changed in recent years. For the purposes of this article we will not discuss removable appliances that are used regularly and successfully for growth modification (functional appliances) or retention (retainers). This article will focus on removables used as active appliances.
\end{abstract}

\section{How removable appliances work}

Removable appliances work by simple tipping movements of the crowns of the teeth about a fulcrum close to the middle of the tooth. They also allow differential eruption

\footnotetext{
$1^{*}$ Consultant in Orthodontics, Department of Orthodontics, St Luke's Hospital, Little Horton Lane, Bradford, BD5 ONA, UK; ${ }^{2}$ General Dental Practitioner, Dental Health Broad Street Practice, 31, Broad Street, Ludlow, Shropshire, SY8 1GR, UK; ${ }^{3}$ Lecture/Honorary Senior Specialist Registrar in Orthodontics, Department of Orthodontics,

University Dental Hospital of Manchester, Higher Cambridge Street, Manchester, M15 6FH, UK;

${ }^{4}$ Consultant in Orthodontics, Department of

Orthodontics, University Dental Hospital of

Manchester, Higher Cambridge Street, Manchester, M15 6FH, UK

${ }^{*}$ Correspondence to: DrS. J. Littlewood email:simonjlittlewood@aol.com

REFEREED PAPER

Received 22.09.00; Accepted 08.05.01

(C) British Dental Journal 2001; 191: 304-310
}

In brief

- Removable appliances are capable of simple tipping movements and allow differential eruption of teeth using biteplanes

- The use of removable appliances are considerably more limited than in the past

- This paper explains the indications for use of removable appliances in contemporary orthodontics

of teeth, for example by using bite planes. They differ from fixed appliances, which are capable of complex movements of multiple teeth, including bodily movement, root torque and rotation.

\section{Advantages and disadvantages of removable appliances \\ Advantages of removable appliances}

- They are removable and therefore easier to clean

- They can provide increased vertical and horizontal anchorage due to palatal coverage

- They can produce efficient over-bite reduction in a growing child

- They can transmit forces to blocks of teeth

Disadvantages of removable appliances

- The appliances can be left out
- Only tilting movements are possible

- They affect speech

- A technician's input is required to make the appliances

- Intermaxillary traction is more difficult

- They are inefficient for multiple tooth movements

- Lower removable appliances are more difficult to tolerate

\section{Lower removable appliances}

Generally these are more difficult to tolerate due to encroachment on the tongue space. Retention of the appliance can also be a problem as the lingual inclination of the molars makes clasping difficult. Consequently, lower removable appliances are generally not recommended and the rest of this article will refer to upper removable appliances only.

\section{Initial popularity of removable appliances}

At the beginning of the twentieth century, orthodontics in the UK was provided using removable appliances that consisted of a vulcanite baseplate that covered the palate and capped the molars and premolars for retention. ${ }^{1}$ Although the materials changed, removable appliances remained the principal appliance for orthodontic treatment in the UK and Europe for the next 70 years. In contrast, the removable appliance had little impact on American orthodontics, which at that time was dominated by Edward Angle. Angle was originally a prosthodontist with an interest in occlusion. Producing an ideal occlusion relied on the ability to exactly position teeth and this required the use of fixed appliances. It was Angle that established orthodontics as a specialty and ran the only postgraduate orthodontic courses in the world at that time. Consequently, Angle's trainees dominated teaching departments in the US for the next 40 years - hence the almost exclusive use of fixed appliances in American orthodontics.

In the UK, the establishment of the 


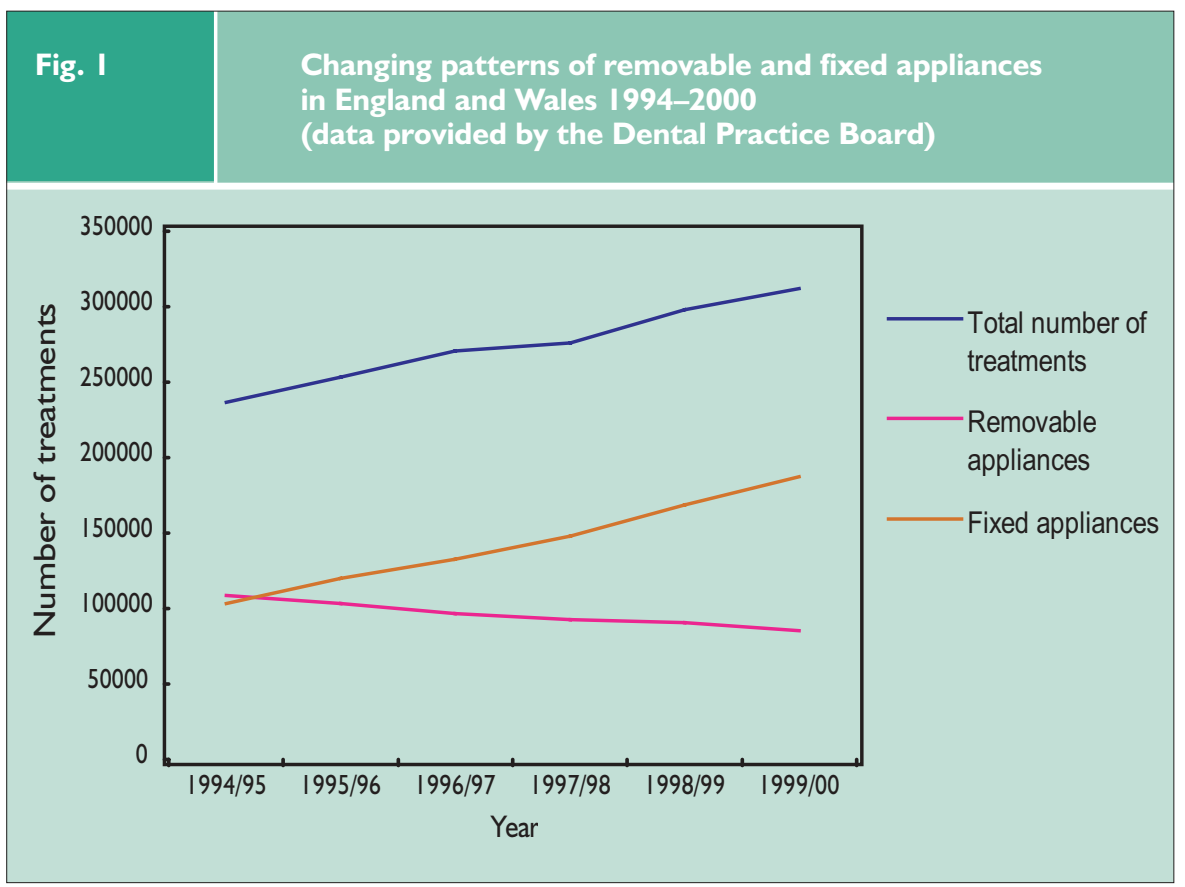

National Health Service in 1948 continued to favour the use of removable appliances. At that time there were only ten specialist orthodontists $^{2}$ so the vast majority of orthodontic treatment was provided by general dental practitioners, who used removable appliances. ${ }^{3}$ At this time a series of orthodontic advisers to the Department of Health, and the then Dental Estimates Board, were of the view that the near exclusive use of removable appliances was the most cost effective way of providing UK orthodontic care. ${ }^{4}$

\section{Declining use of removable appliances}

Since the 1970s, in the UK there has been a decline in the use of removable appliances in favour of fixed appliances. In 1967, 96\% of cases were treated with removable appliances in the General Dental Services of England and Wales. By 1988 this had fallen to $75 \% .{ }^{5}$ A survey of UK consultant orthodontists in 1985 showed that $39 \%$ of treatments involved the use of a removable appliance, either alone or in combination with other appliance systems. However, by 1996 this had reduced to $16 \%{ }^{6}$ Figure 1 demonstrates the changing use of removable appliances and fixed appliances in the past six years.

The move away from the provision of complete orthodontic treatments with removable appliances has occurred for a number of possible reasons.

- In the 1970s, the length of postgraduate orthodontic training increased from one to two years and then in the 1980s to three years. This meant that postgraduates were able to complete supervised treatment of multibanded cases before they qualified.

- A series of technical advances made it much more efficient to use fixed appliances. This included the introduction of prewelded, preformed orthodontic bands and, later, directly bonded attachments. The introduction of the pre-adjusted edgewise bracket reduced the need for complex individually formed archwires. ${ }^{7,8}$

- There was a postboomer reduction of $30 \%$ in the 12 -year-old population in the 1980s. The reduced number of children requiring treatment meant the Dental Practice Board could afford to increase fixed appliance fees to a level where it was financially viable for clinicians to use them under the NHS. ${ }^{9}$

As our understanding of quality of outcome has improved, other factors have influenced the decline of use of removable appliances.

- Measurements of treatment outcomes with removable appliances suggested that the quality of outcome is often not as high as with fixed appliances. ${ }^{10-12}$ Reasons for this will be discussed later.

- There is a higher discontinuation of treatment associated with the use of removable appliances. ${ }^{13,14}$

- Fewer general dental practitioners are now willing to undertake orthodontic treatment and so refer their patients on to specialist orthodontists. As specialist orthodontists favour the use of fixed appliances due to the ability to precisely position teeth, this has resulted in a higher proportion of cases treated with fixed appliances. ${ }^{15}$

\section{Scope of removable appliances}

The use of removable appliances still varies widely between clinicians, but it is possible to achieve adequate occlusal improvement with these appliances, providing that suitable cases are chosen. ${ }^{16}$ It is vital to emphasize that cases suitable for removable appliance treatment are those that require simple tipping movements only, and surprisingly few malocclusions will fall into this category. Compromising this key point can often lead to maltreatment of the malocclu- sion and the patient being worse off than before treatment.

An example of inappropriate use of removable appliances is shown in Figure 2. The upper model shows the compromised result produced by inappropriate use of a removable appliance. The upper first premolars have been extracted and the overjet reduced by tipping the teeth. Since tipping alone is not sufficient in this case the result is poor. Inappropriate use of a removable appliance has simply converted a Class II division 1 incisor relationship to a Class II division 2 incisor relationship. In other words, treatment has converted one orthodontic malocclusion into another.

The rest of this article will address the choice of appropriate cases suitable for treatment with removable appliances. Removable appliances can be used:

- on their own for specific clinical situations, or

- as an adjunct to more complex treatments, such as fixed appliances and headgear.

\section{Use of removable appliances alone}

Removable appliances should not be seen as an appliance for those patients whose oral health or motivation does not reach the standards of fixed appliances. In addition, removable appliances should not be seen as an alternative method of treating complex malocclusions when the clinician has not acquired the necessary skills in fixed appliance therapy. However, although removable appliances can be used by the generalist, they still need to be used with considerable skill and careful monitoring to produce good results. In certain limited 


\section{PRACTICE orthodontics}

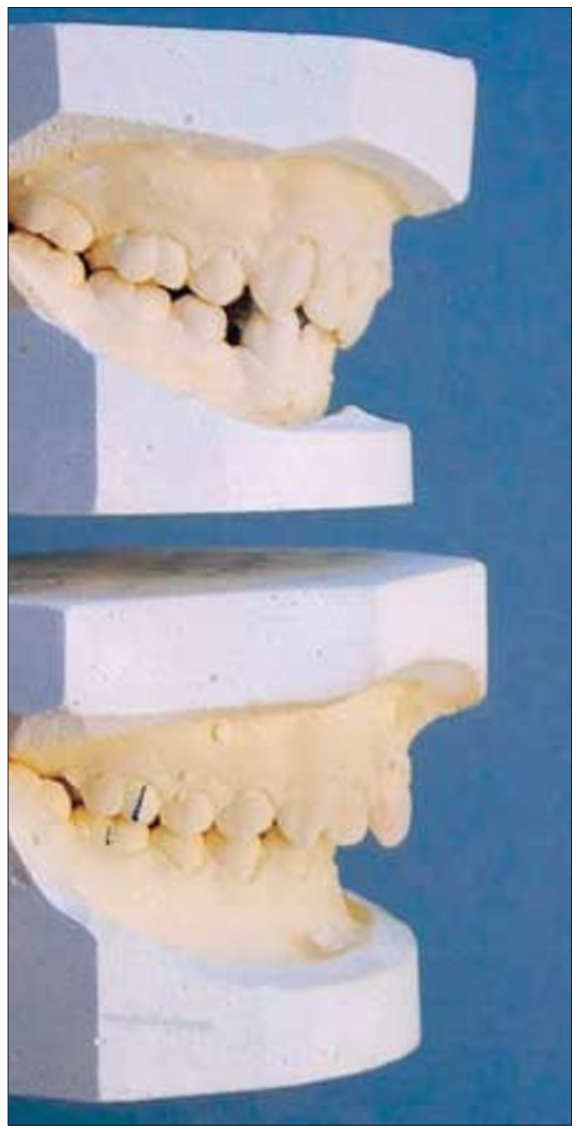

Fig. 2. An example of inappropriate treatment with a removable appliance (top model - after treatment, bottom model - before treatment).

cases they can provide simple, efficient and effective treatment:

- To intercept the development of malocclusions, requiring limited tipping movements, using a single removable appliance in the mixed dentition ${ }^{16}$

- Space maintenance

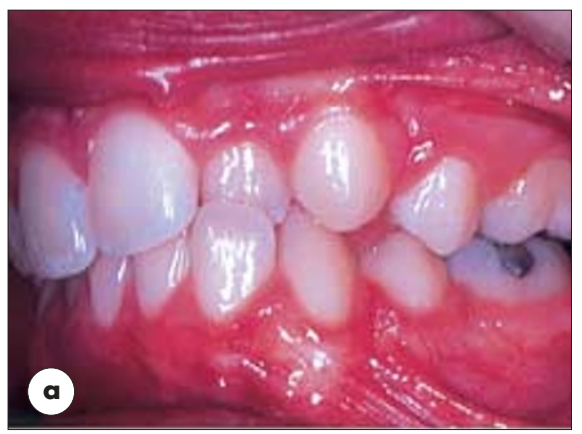

Use in the mixed dentition

Upper removable appliances can be used as an interceptive appliance in the mixed dentition for short, simple treatment. ${ }^{16}$ Examples include correction of cross-bites, which can either be:

- Anterior or

- Posterior

A cross-bite with an associated displacement of the mandible on closure is felt to be a functional indication for orthodontic treatment. It has been suggested that this displacement of the mandible may exacerbate temporomandibular dysfunction in individuals prone to the condition, ${ }^{17}$ although this is by no means conclusively proven. ${ }^{18}$

\section{Anterior cross-bite}

In addition to treating cross-bites with mandibular displacements, correction of an anterior cross-bite may prevent labial displacement of a lower incisor, which could otherwise lead to loss of labial periodontal attachment (Fig. 3). Figure 4 demonstrates simple correction of an upper lateral incisor cross-bite using an upper removable appliance. The active component is a Z-spring.

Figure 5 summarizes the key features required for correction of an anterior crossbite with a removable appliance.

\section{Posterior cross-bite}

A Cochrane systematic review of orthodontic treatment for posterior cross-bites concluded that when grinding of deciduous teeth alone is not effective, using an upper removable expansion appliance to expand the upper arch will decrease the risk of a

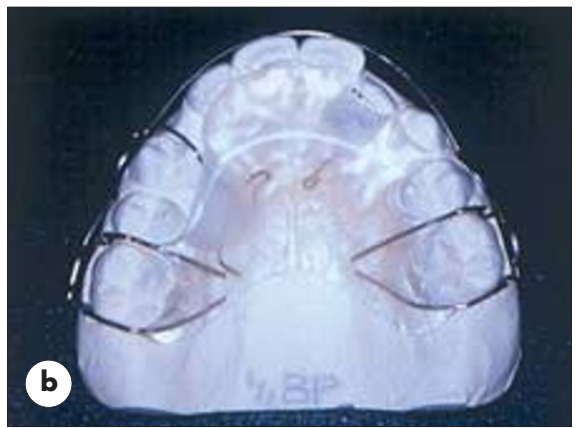

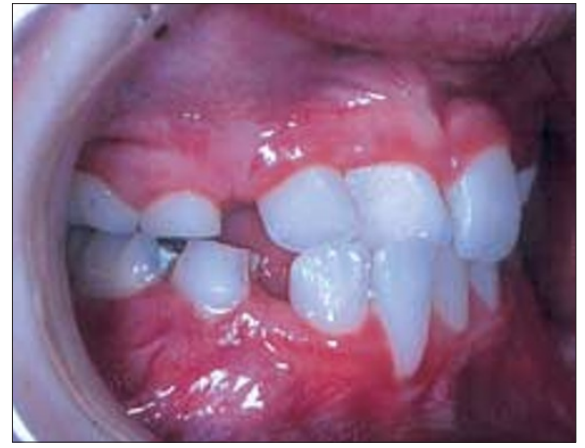

Fig. 3. Loss of labial periodontal support on lower incisor due to anterior cross-bite.

posterior cross-bite from being perpetuated into the permanent dentition. ${ }^{19}$

Ideally there should be positive interlock of the cusps after expansion to prevent relapse. ${ }^{20}$ Also, the transverse skeletal relationship should ideally be normal - in other words the cross-bite is dental in origin, rather than due to an underlying skeletal problem. Consequently, correction of unilateral cross-bites may be possible with a removable appliance, but not bilateral cross-bites. This is because treatment will require more than simple tipping alone.

Figure 6 demonstrates a suitable case for correction of a posterior cross-bite with a removable appliance. The patient is in the mixed dentition with a unilateral cross-bite on the left. There is a displacement of the mandible to the left on closure (note the deviation of the lower centre-line to the left). An upper removable appliance with a midline screw is used to expand the upper arch. Once the upper arch is corrected transversely, the mandibular displacement is removed and the centre-line self-corrects.

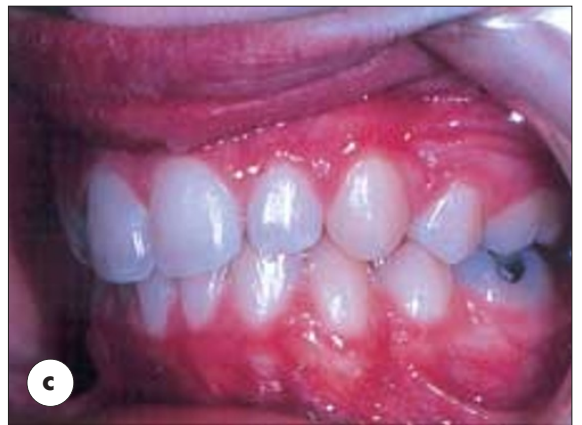

Fig. 4. (a) Upper lateral incisor in cross-bite. (b) Upper removable appliance used to procline the lateral incisor over the bite. (c) Corrected cross-bite. 
Correction of simple anterior or posterior cross-bites is possible with removable appliances as described above, but these problems can also be corrected with fixed appliances. While both approaches can be successful, there is insufficient evidence at present to indicate which is the better technique.

\section{Space maintainers}

These are used to maintain space when teeth have been lost prematurely. The commonest reason for premature loss of teeth is caries as a result of poor diet and poor oral care. Consequently, these patients are often not ideal candidates for wearing appliances. In addition, wearing a space maintainer is a drain on the patient's compliance, which could compromise any future orthodontic treatment. Space maintainers can be used, but case selection must be appropriate. It is therefore suggested that space maintainers should be used in cases where they will prevent, or significantly reduce, the need for orthodontic treatment at a later stage. A good example of this is the use of a removable appliance with a prosthetic tooth to maintain the space, and retain aesthetics, in a patient who has prematurely lost an upper incisor as a result of trauma. This will also prevent a shift of the midline.

\section{Use of removable appliances as an adjunct to more complex treatment} The previous section has discussed specific clinical situations when it is possible to correct malocclusions using removable appliances alone. These uses have been devised by investigating the results, retrospectively, of removable appliance treatments using occlusal indices. ${ }^{5,10,16,21}$ However, the use

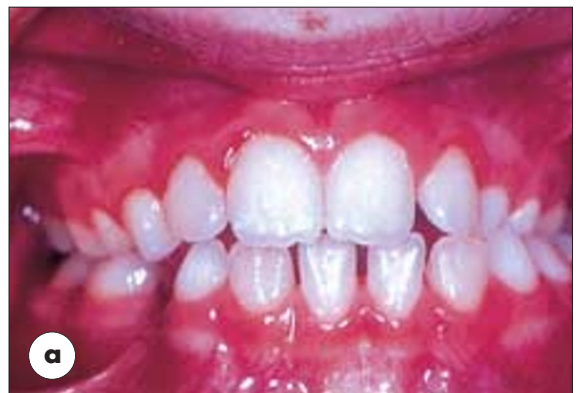
with a removable appliance

I. Adequate overbite. A positive overbite must be present post-treatment in order to provide a stable result.

2. Adequate space into which the incisor can be tipped.

3. Class I or mild Class III skeletal pattern.

4. Correct inclination of the incisors. As the treatment is aimed at tipping the upper incisors forwards the initial inclination of the incisors should ideally be slightly retroclined. If this is not the case the upper incisors will be excessively proclined, which can be unaesthetic and result in unfavourable loading of the teeth in function.

5. A periapical radiograph may be required before treatment to check for supernumerary teeth, or in the case of a lateral incisor, an overlying unerupted canine.

of removables as an adjunct to more complex treatments is more opinion based. Many clinicians use them to enhance the effect of fixed appliances, headgear or in preparation for functional appliances. Further clinical research is required to ascertain whether the use of removable appliances as an adjunct to more complex treatment enhances the efficiency and quality of the final result. Table 1 illustrates some clinical examples of removable appliances used in preparation for, or in conjunction with, more complex treatments.

\section{Conclusion}

The contemporary uses of removable appliances are considerably more limited than in the past. This is due to the recognition of their limitations. They should not be used as a second choice to fixed appliances. Specific indications for their sole use in the mixed dentition have been described based on investigation of results using occlusal indices. Removable appli-

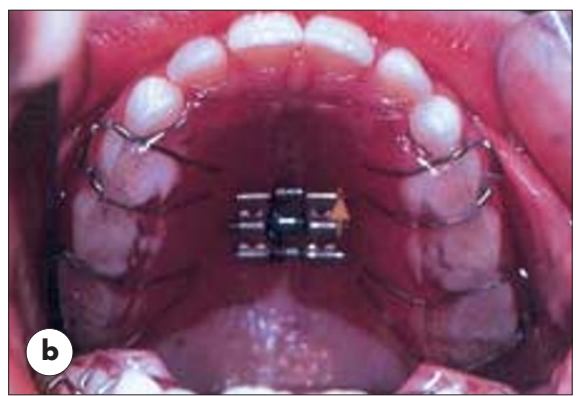

ances can also be used in conjunction with more complex treatments, but further research is required to confirm whether this enhances the quality and efficiency of treatment or not.

No formal, national guidelines currently exist on the use of removable appliances. However, the paper was discussed with, and approved by, the Development and Standards Committee of the British Orthodontic Society. The authors would like to thank the members of this committee for their helpful input into this paper. We would also like to thank Laura Mitchell for the photographs in Figures 3, 4, 5 and 6.

1 Colyer J F. Notes on the treatment of irregularities in position of the teeth. London: The Dental manufacturing company, 1900.

2 Kerr W J S. The first orthodontic diploma. Br Dent J 2000; 188: 299-300.

3 Hoyle A. The development of removable appliances in the United Kingdom. Br J Orthod 1983; 10: 73-77.

4 Hooper J D. Orthodontics as a public service: The Wessex survey. Transactions of the British Society for the Study of Orthodontics 1967: 1-10.

5 Kerr W J S, Buchanan I B, McColl J H. Use of the PAR index in assessing the effectiveness of removable orthodontic appliances. Br J Orthod 1993; 20: 351-357.

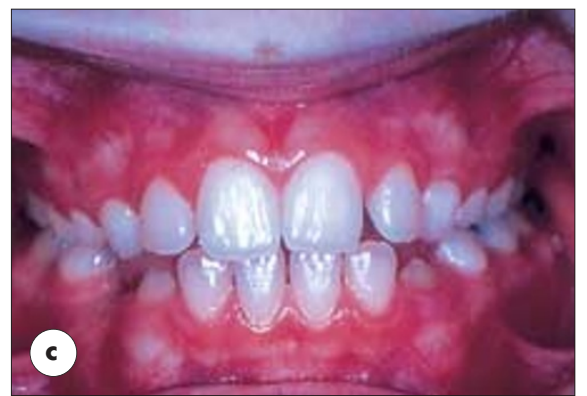

Fig. 6. (a) Unilateral cross-bite left side with an associated displacement of the mandible to the left. (b) Upper removable appliance with midline screw. (c) Corrected cross-bite (note correction of centre-line). 


\section{Table I \\ Use of upper removable appliances (URA) as an adjunct to more complex treatment}

\begin{tabular}{|l|l|l|}
\hline $\begin{array}{l}\text { Removable used } \\
\text { in addition to: }\end{array}$ & $\begin{array}{l}\text { Clinical problem to } \\
\text { be addressed }\end{array}$ & Comments \\
\hline Headgear & Class II molars & $\begin{array}{l}\text { An URA with palatal finger springs to } \\
\text { the first permanent molars can be } \\
\text { used to enhance the distal movement } \\
\text { obtained with the headgear. This type } \\
\text { of URA can be used without headgear } \\
\text { to derotate mesiopalatally rotated } \\
\text { molars into a Class I relationship22, } \\
\text { but without headgear no actual } \\
\text { distalisation occurs. }\end{array}$ \\
\hline
\end{tabular}

Fixed appliances Deep over-bite An URA with a flat anterior biteplane used with a lower fixed appliance or in addition to upper and lower fixed appliances. It can also be used to prevent occlusal forces debonding lower fixed appliance components.

Functional appliance
Vertical anchorage required

Horizontal anchorage required

Retroclined incisors

For example, when bringing down high ectopic canines

For example, when upper first molars are extracted an URA can prevent mesial movement of upper second molars whilst retracting premolars. Careful anchorage management with fixed appliances is then required.

Retroclined incisors can be proclined in preparation for functional treatment in Class II division 2 cases $^{23}$

Posterior cross-bite

\section{Maintenance of} sagittal correction
Initial expansion with a removable appliance has been used 23 (although it is possible to incorporate this into a Twin Block appliance)

Following treatment with a functional appliance a clip-over inclined bite plane can be used during the second stage with fixed appliance to maintain the sagittal correction 24
6 Russell J I, Pearson A I, Bowden D E J, Wright J and O'Brien K D. A survey of consultant orthodontists. Br Dent J 1999; 187: 149-153.

7 Andrews L F. The straight wire appliance: explained and compared. J Clin Orthod 1976; 10: 174-195.

8 McLaughlin R P, Bennett J C. The transition from standard edgewise to preadjusted appliance systems. J Clin Orthod 1989; 23: 142-153.

9 Robertson N R E, Hoyle B A. Orthodontic
Treatment - Time for a Change? Br J Orthod 1983; 10: 154-156.

10 Tang E L K, Wei S H Y. Assessing treatment effectiveness of removable and fixed orthodontic appliances with the occlusal index. Am J Orthod Dentofac Orthop 1990; 99: 550-556

11 O'Brien K D, Shaw W C, Roberts C T. The use of occlusal indices in assessing the provision of orthodontic treatment by the hospital orthodontic service of England and Wales. $\mathrm{Br}$ Orthod 1993; 20: 25-35.
12 Richmond S, Shaw W C, Stephens C V, Webb W G, Roberts C T, Andrews M. Orthodontics in the General Dental Services in England and Wales: a critical assessment of standards. $\mathrm{Br}$ Dent J 1993; 174: 315-329.

13 Murray A M. Discontinuation of orthodontic treatment: a study of contributing factors. $\mathrm{BrJ}$ Orthod 1989; 16: 1-7.

14 Wilmott D R, DiBiase D, Birnie D J, Heesterman R A. The Consultant Orthodontists' Group Survey of hospital waiting lists and treated cases. Br J Orthod 1995; 22: 53-57.

15 Stephens C D, Harradine N W. Changes in the complexity of orthodontic treatment for patients referred to a teaching hospital. $\mathrm{BrJ}$ Orthod 1988; 15: 27-32.

16 Kerr W J S, McColl J H, Frostick L. The use of removable orthodontic appliances in the General Dental Service. Br Dent J 1996; 181: 18-22.

17 Mohlin B, Thilander B. The importance of the relationship between malocclusion and mandibular dysfunction and some clinical applications in adults. Eur J Orthod 1984; 6: 192-204.

18 Luther F. Orthodontics and the temperomandibular joint: where are we now? Part 2. Functional occlusion, malocclusion and TMD. Angle Orthod 1998; 68: 305-318.

19 Harrison J E, Ashby D. Orthodontic treatment for posterior crossbites (Cochrane Review). In: The Cochrane Library, Issue 2, Oxford: Update Software, 2000.

20 McDonald F, Ireland A J. Diagnosis or the orthodontic patient. pp111-117. Oxford University Press, 1998.

21 Kerr W J S, Buchanan I B, McNair F I, McColl J H. Factors influencing the outcome and duration of removable appliance treatment. Eur J Orthod 1994; 16: 181-186.

22 Lewis D H, Fox N A. Distal movement without headgear: The use of an upper removable appliance for the retraction of upper first molars. Br J Orthod 1996; 23: 305-312.

23 Turner P J. Use of removable appliances as an adjunct to fixed appliance therapy. Dent Update 1993; 20; 428-432.

24 Sandler P J, DiBiase D. The inclined bite-plane - a useful tool. Am J Orthod Dentofac Orthop 1996; 110: 339-350. 